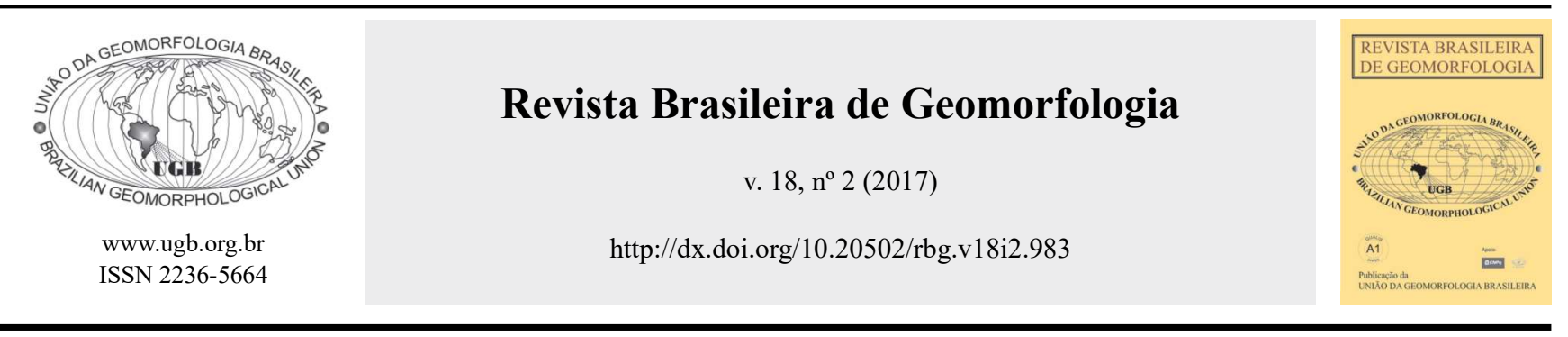

\title{
MICROMORFOLOGIA DE COLÚVIOS EM SEQUENCIAS \\ PEDOESTRATIGRÁFICA E LITOESTRATIGRÁFICA - O CASO \\ DAS SUPERFÍCIES DE PALMAS/ÁGUA DOCE (SUL) E PLANALTO \\ SEDIMENTAR DO ARARIPE (NORDESTE DO BRASIL)
}

\section{MICROMORPHOLOGICAL OF COLLUVIUM IN SEQUENCES PEDOESTRATIGRAPHIC AND LITHOSTRATIGRAPHIC - THE CASE OF PALMAS/ÁGUA DOCE(SUL) AND THE ARARIPE SEDIMENTARY PLATEAU (BRAZIL NORTH-EAST)}

Flávia Jorge de Lima

Departamento de Geografia, Universidade Estadual do Oeste do Paraná Rua Maringá, 1200, Francisco Beltrão, Paraná. CEP 85.605-010. Brasil Email: flavialimageo@gmail.com

Julio Cesar Paisani

Departamento de Geografia, Universidade Estadual do Oeste do Paraná Rua Maringá, 1200, Francisco Beltrão, Paraná. CEP 85.605-010. Brasil Email: juliopaisani@hotmail.com

Antonio Carlos de Barros Corrêa

Departamento de Geografia, Universidade Federal de Pernambuco Av. Prof. Moraes Rego, 1235, Recife, Pernambuco. CEP: 50670-901. Brasil

Email:dbiase2001@terra.com.br

Marga Eliz Pontelli

Departamento de Geografia, Universidade Estadual do Oeste do Paraná Rua Maringá, 1200, Francisco Beltrão, Paraná. CEP 85.605-010. Brasil Email:mepontelli@hotmail.com

Informações sobre o Artigo

Recebido (Received):

13/01/2016

Aceito (Accepted):

07/03/2017

Palavras-chave:

Propriedades Micromorfológicas; Significado Paleoambiental; Quaternário Superior.

\section{Resumo:}

Este artigo identificou propriedades micromorfológicas comuns em depósitos de colúvio formados por diferentes processos e condições ambientais, com o intuito de obter informações que auxiliem no reconhecimento de microfeições indicadoras de ambiente úmido. Para tanto foram comparadas uma seção estratigráfica do Planalto Sedimentar do Araripe com os elementos micromorfológicos do nível 4Cb da seção HS1 na superfície Palmas/Água Doce - Sul do Brasil, gerados na passagem de condições paleoclimáticas secas para úmidas. Os métodos incluem: i) descrição com base no critério litoestratigráfico para seção Rampa de colúvio de fácie proximal - CSM-C, e no pedoestratigráfico para a seção HS1; 


\section{Keywords:}

Micromorphological Properties; Paleoenvironmental Significance; Upper Quaternary. ii) caracterização das propriedades sedimentológicas; iii) - Descrição e análise micromorfológica dos materiais. O nível $4 \mathrm{Cb}$ foi usado como referência por ser de origem coluvial e o principal responsável pela colmatação de um paleocanal de segunda ordem. Comparando a unidade $4 \mathrm{Cb}$, gerada em condições ambientais transicionais de clima mais seco para mais úmido, com a seção CSM-C, pode-

se concluir que: I) a componente água esteve presente em ambas unidades coluviais, tanto durante quanto após o evento deposicional. Isto demonstra que ambas têm importante significado paleoambiental, sobretudo para o sul do Ceará, que está inserido no contexto semiárido. II) as evidências micromorfológicas comuns de depleção e migração de oxihidróxido de ferro permitem apontar que as condições paleoambientais de formação dos colúvios foram similares, gerados na transição de um ambiente mais seco para mais úmido. III) o acúmulo das microfeições hidromórficas e de migração dos oxihidróxidos de ferro com aberturas de poros testemunham a continuidade da presença da água no sistema.

\begin{abstract}
:
This work has identified micromorphological properties common to colluvial deposits formed by different processes and environmental conditions, aiming at obtaining information that help the recognition of humid environment indicator micro-features. For this purpose, a stratigraphic section at Araripe sedimentary plateau was compared to the micromorphological elements of 4Cb level within HS1 section of the Palmas/Água Doce surface, southern Brazil, generated under the shift from dry to humid paleoclimatic conditions. The applied methods comprise: i) description based on lithostratigraphical and pedostratigraphical criteria of colluvial ramp proximal facies CSM-C and section HS1 respectively; ii) sedimentological characterization; iii) - micromorphological description and analysis of materials. Level $4 \mathrm{Cb}$ was used as a reference due to its colluvial origin as well as for infilling a second order paleo-channel. By comparing $4 \mathrm{Cb}$ unit, generated in transitional environmental conditions from a drier to a wetter climate, to CSM-C section one may conclude that: I) water was present in both colluvial units, both during and after the depositional event. This demonstrates that both have important paleoenvironmental significance, especially for the south of Ceará State, which is inserted in the semi-arid context. II) the common micromorphological evidences of depletion and migration of iron oxyhydroxides point to similar colluvium forming paeloenvironmental conditions, both being generated within a transition from drier to wetter conditions. III) the accumulation of hydromorphic micro-features coupled and the migration of iron oxyhydroxides coupled with the opening of pore spaces testify to the presence of water within the system.
\end{abstract}

\section{Introdução}

O termo colúvio envolve diferentes materiais gerados e depositados no ambiente de encosta, cuja geometria permite a acomodação dos sedimentos próximos e em sua base, dentro do contexto climático em que o evento foi desencadeado (BIGARELLA et al, 1965; GOUDIE e BULL, 1984; SELBY,1985; THOMAS, 1994; CORREA, 2001; SUGUIO, 2003; MILLAR, 2006; LEOPOLD e VÖLKEL, 2007; BIGARELLA et al, 2009; MÜCHER et al, 2010; MOURA e SILVA, 2011). Interpretados como unidades deposicionais que registram as mudanças climáticas pretéritas (MOUSINHO e BIGARELLA, 1965; MODENESI e TOLEDO, 1996), Paisani et al (2014) ressaltam que essas unidades nem sempre testemunham tais mudanças, mas apenas uma adequação do sistema geomórfico às oscilações dentro de uma fase climática (CORREA, 2001; THOMAS, 1994). Independente dos fatores envolvidos e do papel do clima, esses materiais revelam a ação da morfogênese, modelando as superfícies geomorfológicas, a qual pode ser de intensidade variável e específica de cada ambiente (PAISANI e PONTELLI, 2012).

Os colúvios, sendo essenciais aos estudos que tratam da dinâmica e evolução das encostas em um dado contexto geomorfológico, sob a égide do modelo processo-resposta, no qual os processos são definidos pelo tipo de energia atuante no sistema e regulados pelas características fisiográficas da paisagem, vêm sendo amplamente adotados como ferramenta elucidativa da história geomórfica recente das paisagens, em especial, as contidas nos trópicos (THOMAS, 1994), como é o caso do Brasil. 
Nesse contexto sublinham-se os trabalhos desenvolvidos no semiárido nordestino, no entorno do Planalto da Borborema, em que esses depósitos, embora espacialmente descontínuos e por vezes tênues, têm sido tema de pesquisas na tentativa de compreender o quadro evolutivo das diferentes formas de relevo cambiadas por condições paleoclimáticas no Quaternário Superior. Sobre essa temática destacam-se as contribuições de Andrade (1958), Andrade e Lins (1963), Mabesoone (1966), Mabesoone e Castro (1975), Corrêa (2001) Peulvast e Claudino-Sales (2002), Bezerra et al. (2008), Silva (2007, 2013), Mutzemberg (2010), Tavares (2010; 2015), Galvão (2012), Fonseca (2012) e Gurgel et al (2013).

Pesquisas também vêm sendo realizadas em ambientes subúmidos encravados no contexto regional semiárido, como é o caso do trabalho de Lima (2015) e Ranulpho (no prelo), que estudam os depósitos de encostas na Chapada do Araripe - Crato e Barbalha, sul do Ceará. Lima (2015) reconheceu que eventos de alta magnitude pluviométrica atingiram a área ocasionando movimentos de massa do tipo fluxos de lama e detrito. Essa remobilização maciça testemunha momento de forte instabilidade nas encostas, coincidindo com o período de máxima reumidificação verificada por Corrêa (2001) e Tavares (2015) para o Maciço da Serra da Baixa Verde, PE. Compatibiliza também com o retorno da umidade para o Nordeste aferida para a transição Pleistoceno/ Holoceno, conforme Barreto (1996), De Oliveira et al (1999), Behling et al (2000), Mutzenberg (2007; 2010) e Silva (2013). Segundo os pesquisadores acima, esse momento foi marcado por condições climáticas mais úmidas e quentes, com precipitações de alta magnitude.

Tais postulações remetem ao modelo de Knox (1972), no qual se defende que os processos de maior atividade nas encostas ocorrem na transição de um clima mais seco para mais úmido, antes que a cobertura vegetal sofra expansão a fim de atingir um novo estágio de clímax frente às condições mesológicas mais favoráveis. Assim, o trabalho geomorfológico é máximo durante a fase de histerese ambiental, na qual os elementos estruturadores da paisagem se reorganizam. Atingido um novo momento de expansão máxima da vegetação, os processos erosivo-deposicionais alcançam um novo platô de equilíbrio que só será novamente rompido em outro momento de transição climática. Situação similar foi verificada para a superfície de Palmas/Água Doce no sul do Brasil, que a partir da passagem do Último Máximo Glacial, clima mais frio e seco, para Holoceno
Inferior, mais quente e úmido, iniciaram movimentos de massa na área (PAISANI et al., 2013b; 2014). Esses movimentos de massa foram recorrentes ao longo de todo o Holoceno a diferentes taxas (PAISANI et al, 2016).

A compreensão dos processos envolvidos durante e após os eventos geradores de instabilidade nas encostas pode ser alcançada a partir de uma análise pormenorizada dos materiais coluviais e colúvio-aluviais. $\mathrm{Na}$ tentativa de elucidar os processos de encosta e encosta-canal, o Grupo de pesquisa Gênese e Evolução de Superfícies Geomórficas e Formações Superficiais, cadastrado no CNPq e formado na Universidade Estadual do Oeste do Paraná (UNIOESTE) vem, nos últimos anos, utilizando-se das propriedades micromorfológicas para caracterizar os aspectos estratigráficos e descrever o comportamento do ambiente às situações alternadas de instabilidades e estabilidades morfo-pedogenética da paisagem (PAISANI e PONTELLI, 2012; PAISANI et al. 2013a; 2014; 2016).

A micromorfologia, desenvolvida com o propósito de entender a organização microscópica dos diferentes tipos de solos (CASTRO, 2008; STOOPS, 2003, 2010; CHURCHMAN, 2013), revelou-se eficiente na caracterização de materiais alóctones, uma vez que permite reconhecer feições ligadas a processos deposicionais (STOOPS, 2010). Com isso, a micromorfologia experimenta uma larga aplicação no estudo de paleossolos de origem poligenética como registro de mudanças ambientais (KEMP, 1999; MESTDAGH et al, 1999; WIEDER e GVIRTZMAN, 1999; PAISANI, 2004; PONTELLI, 2005; KÜHN e PIETSCH, 2013; PAISANI et al, 2013a; 2014), assim como na caracterização dos diferentes depósitos quaternários (BERTRAN e TEXIER, 1999; FERREIRA e OLIVEIRA, 2006; MILLAR, 2006; MROCZEK e RODZIK, 2011; PAISANI e PONTELLI, 2012; PAISANI et al, 2016); ARAÙJO et al, 2013). A micromorfologia em colúvios permite identificar os processos deposicionais pretéritos e atuais, a gênese do material fonte e as transformações pós-deposicionais (PAISANI e PONTELLI, 2012). Todavia, embora reconhecida a potencialidade da micromorfologia dos solos na caracterização dos depósitos quaternários, fornecendo chaves interpretativas de uma sequência de eventos, ainda são poucos os estudos que a adotam com a devida relevância. De fato, isso se alinha com a afirmação de que ainda é muito limitado o conhecimento de feições micromorfológicas específicas de depósitos de encostas (MÜCHER et al, 2010).

Assim, a micromorfologia assume um papel 
importante nesse tipo de pesquisa, contribuindo substancialmente na identificação dos eventos e condições ambientais envolvidas na geração e manutenção dos materiais na superfície. Com base nisso, objetiva-se identificar propriedades micromorfológicas comuns em depósitos de colúvio gerados por diferentes processos e condições ambientais, com o intuito de obter informações que auxiliem no reconhecimento de microfeições de ambiente úmido na seção do Planalto Sedimentar do Araripe, usando como referência informações micromorfológicas obtidas de sequência pedoestratigráfica, cujos depósitos de colúvio foram gerados na passagem de condições paleoclimáticas secas para úmidas no Sul do Brasil (PAISANI et al. 2013b; 2014; 2016).

\section{2. Áreas de estudo, Materiais e Métodos}

\subsection{Localização e aspectos gerais das áreas de estudo}

Os depósitos de colúvio estudados se situam em dois contextos ambientais modernos distintos. O primeiro se encontra em divisor de águas regional na superfície de Palmas/Água Doce, sul do Brasil (Figura 1). O segundo encontra-se no compartimento de encosta do Planalto Sedimentar do Araripe, sul do Ceará (Figura 1).

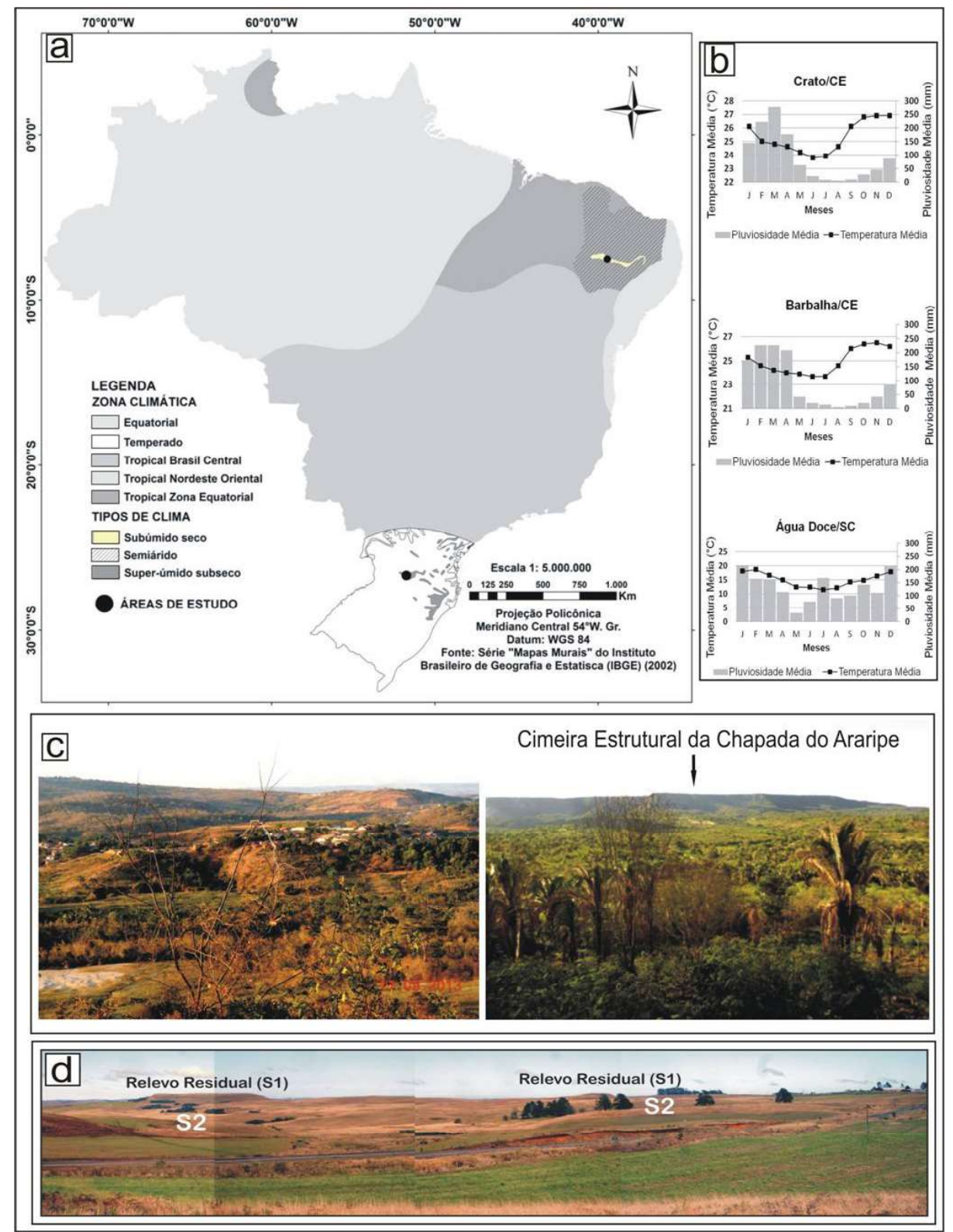

Figura 1 - Áreas de estudo. (a) Zona climática e tipos de clima; (b) Médias de pluviosidade e temperatura: Crato - Adaptado por VAREJÃO-SILVA (1990) e extraído FUNCEME (2012); Barbalha - Normais Climatológicas do Brasil 1961-1990 (INMET,2015); Agua Doce - Estação Meteorológica de Palmas (PAISANI et al. 2012); (c) Vista da paisagem do Planalto sedimentar do Araripe; (d) Vista da paisagem do Planalto Palmas (PR)/Água Doce (SC) 
A superfície de Palmas/Água Doce é estruturada sobre riolitos EoCretáeos do Grupo Serra Geral (NARDY et al., 2002). Essa superfície está acima de $1.200 \mathrm{~m}$ de altitude e tem colinas convexas, mantidas tanto pelo substrato quanto por colúvios. Sua paisagem é caracterizada por fundos de vales abertos e em canyons, que exibem solos hidromórficos do Holoceno Superior, encostas com rampas de colúvio e paleovales de baixa ordem com paleossolos hidromórficos (GUERRA e PAISANI, 2012; PAISANI et al., 2012; 2013b; 2014). Tal paisagem se distingue no contexto regional pela presença da vegetação de Campo nas colinas e Floresta Ombrófla Mista com Araucárias nos fundos dos vales de alta ordem hierárquica e pelo clima subtropical do tipo Cfa, conforme classificação de Köppen (MAACK, 1981). Trata-se de um clima localmente super-úmido subseco (Figura 1a) (IBGE, 2002), com precipitação média anual de $1.590 \mathrm{~mm}$, bem distribuída e temperatura média anual de $15^{\circ} \mathrm{C}$ (PAISANI et al., 2014). A presença de campo nessa superfície tem sido tema de discussões paleoclimáticas (MAACK, 1948; 1949; BEHLING et al., 2004) e ainda é uma questão em aberto. De todo modo, os campos estão presentes na área pelo menos nos últimos 41.000 anos AP e expressam uma estreita relação entre fatores edáficos, antrópicos e climáticos (PAISANI et al., 2013a; 2014).

Já o Planalto Sedimentar do Araripe, cuja cimeira estrutural está em torno de 960 metros, compreende uma das superfícies elevadas do interior do nordeste e é sustentado pelos terrenos paleo-mesozóicos da Bacia Sedimentar do Araripe (sub bacia leste - vale do Cariri), uma bacia intracratônica do tipo rifte (SOUZA, 2000; NEUMANN et al., 2003; SILVA et al, 2003). Essa morfoestrutura encontra-se modelada em superfícies mantidas tanto pelo material sedimentar da bacia quanto pelas coberturas quaternárias na forma de colúvio, colúvio-alúvio e alúvio. São superfícies demarcadas na paisagem por colinas convexas alongadas, encostas dissecadas com rampas de colúvio, fundos de vales abertos, planícies e glacis dissecados (LIMA, 2015). A paisagem também se destaca por dois fatores: a composição fitogeográfica e tipo de clima. O primeiro, por apresentar um arranjo vegetal, é composto pelas seguintes fisionomias: Cerrado/cerradão e mata úmida a partir da cota de 700m; mata seca na média encosta; e caatinga arbórea-arbustiva na baixa encosta em direção às áreas de planícies, onde existem fragmentos de mata ciliar (ANDRADE-LIMA,1966; FUNCEME, 2006;
FERNANDES, 2006). O segundo, pela diferenciação climática em relação ao contexto geral semiárido, que devido à influência direta do efeito orográfico do planalto, exibe um topoclima, cuja fisionomia da paisagem denuncia, de imediato, as alterações nos padrões de temperatura e umidade. Conforme classificação de Köppen, trata-se de um clima tropical chuvoso, tipo Aw, subúmido seco (IBGE, 2002; FUNCEME, 2012; 2015) com estação chuvosa no verão/outono. As temperaturas médias anuais oscilam entre 23 a $27^{\circ} \mathrm{C}$ e a pluviosidade média anual entre 1000 e $1.100 \mathrm{~mm}$.

\subsection{Descrição Macroscópica}

Os materiais do paleocanal de $2^{\mathrm{a}}$ ordem foram, inicialmente, individualizados e caracterizados conjugando critérios lito, pedo e aloestratigráfico (PAISANI et al., 2012). Na sequência, em razão do reconhecimento de níveis de paleossolos e visando estabelecer correlações estratigráficas com outras seções mapeadas na área, passou-se a utilizar o critério e nomenclatura pedoestratigráfico para distinguir e classificar as unidades (PAISANI et al., 2014). Das vinte seções descritas na área, a seção em foco tem a seguinte nomenclatura: Seção HS1. O horizonte $4 \mathrm{Cb}$, de origem coluvial gerado por fluxo de lama, assume destaque por ser o principal responsável pela colmatação do paleocanal de $2^{\mathrm{a}}$ ordem (PAISANI et al., 2012;). Além disso, registra um período de morfogênese intensa que foi capaz de romper com a fase anterior de estabilidade pedogenética, reconhecida pelo desenvolvimento de níveis de paleossolos. Assim, a assinatura estratigráfica da unidade $4 \mathrm{Cb}$ imbui-se de um importante significado paleoambiental regional. Por este motivo, tal nível pedoestratigráfico, incorporando a transição inferior $(4 \mathrm{Cb} / 5 \mathrm{Cb})$ e superior $(4 \mathrm{Cb} / 3 \mathrm{Cb})$, foi selecionado para a análise micromorfológica (Figura 2a).

Já o depósito de colúvio fácie proximal foi descrito utilizando-se de critérios litoestratigráficos (LIMA, 2015), uma vez que não foi reconhecido paleossolo. Esta seção encontra-se exposta em corte de estrada e foi atribuído o código de campo CSM-C. Tal depósito destaca-se pela dimensão dos blocos que, a primeira vista, denuncia a alta energia envolvida na remobilização dos materiais, coincidindo com período de retorno da umidade para o Nordeste (Transição Pleistoceno/ Holoceno/Holoceno Inferior), atualmente semiárido. Situado em ambiente moderno subúmido, foi selecio- 
nado com o intuito de obter informações que auxiliem na interpretação dos processos que geraram os depósitos em momentos de reumidificação e que hoje estão estruturando a paisagem. A determinação das classes texturais das unidades foi realizada em laboratório da seguinte forma: da sequência pedoestratigráfica de paleocanal de $2^{\mathrm{a}}$ ordem do Sul do Brasil, foi usado o diagrama de Flemming (2000), em que foram plotados os dados granulométricos obtidos pelo clássico método de peneiramento e pipetagem com separação via úmida (SUGUIO, 1973); da sequência litoestratigráfica, foi usado o diagrama de Shepard (1954), cujos dados granulométricos foram obtidos com base no método de Gale e Hoare (1991).

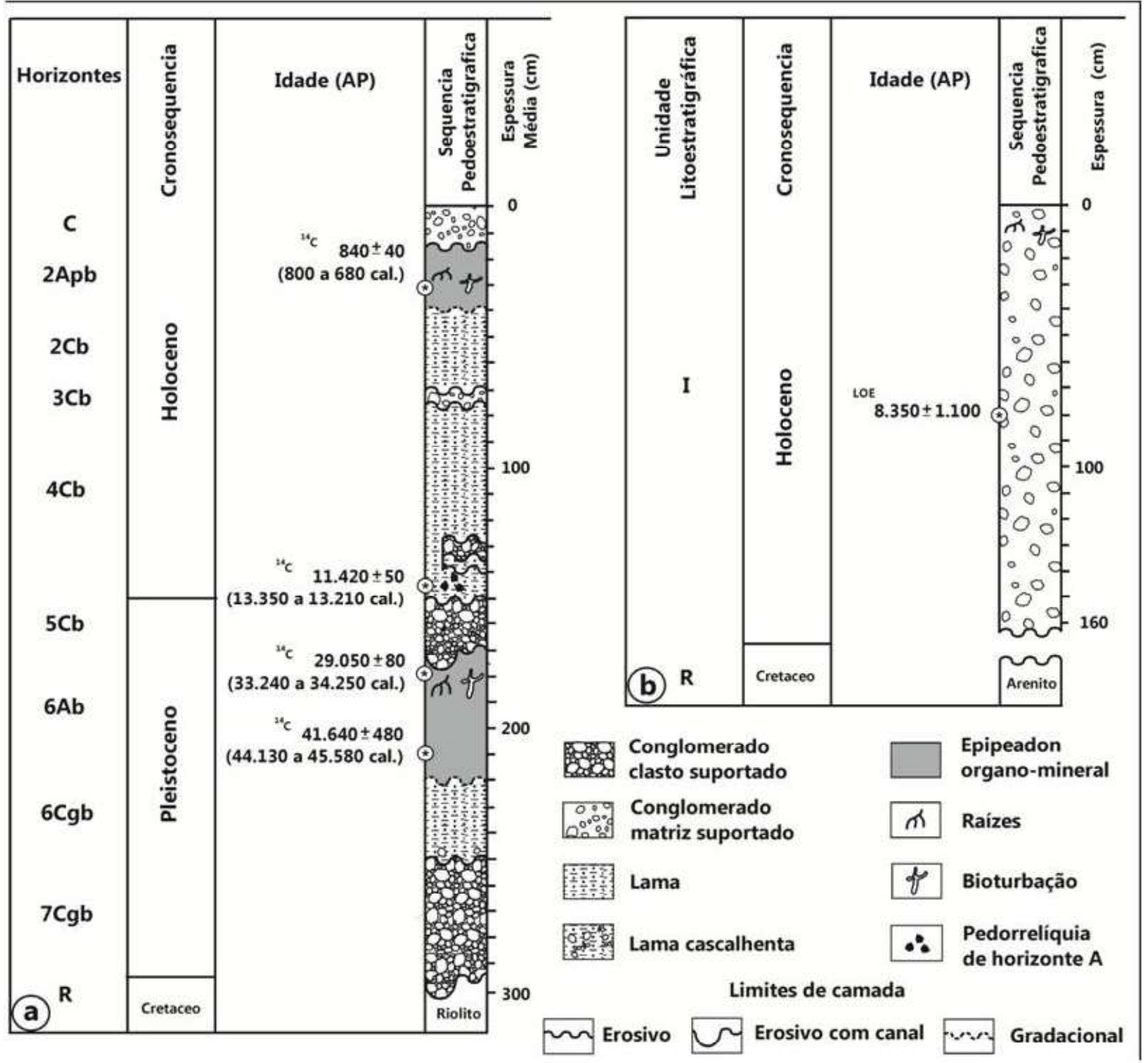

Figura 2 - (a) Seção pedoestratigráfica de paleofundo de vale de segunda ordem (HS1) na superficie Palmas/Agua Doce - Sul do Brasil (Adaptado de PAISANI et al., 2014). (b) Seção litoestratigráfica de fácie proximal de rampa de colúvio no Planalto Sedimentar do Araripe - NE do Brasil (Adaptado de LIMA, 2015).

\subsection{Descrição Microscópica}

A descrição e interpretação micromorfológica dos materiais demandou duas etapas iniciais: coleta e impregnação das amostras indeformadas; e confec- ção de lâminas delgadas. As amostras da seção HS1 foram preparadas de acordo com Castro (1985) pelo Laboratório de Micromorfologia do Departamento de Geociências UNICAMP, enquanto a amostra da 
seção CSM-C foi confeccionada no laboratório de preparação de lâminas delgadas do Departamento de Geologia - Centro de Tecnologia e Geociências da Universidade Federal do Pernambuco - UFPE. As lâminas foram analisadas no microscópio petrográfico trinocular Leica DM 2500 P, com câmera Leica EC 3 acoplada, e do software Leica Application Suíte - LAS EZ versão 1.4 do Laboratório de Microscopia Ótica da UNIOESTE, Campus Francisco Beltrão. O método de análise é qualitativo, carecendo de um tratamento criterioso e pormenorizado dos dados.

A organização microscópica dos materiais é compreendida a partir do arranjo das feições pedológicas e da distribuição relativa dos constituintes (DRC) denominados de esqueleto (E), plasma (Pm) e poros (P), cujos dois primeiros correspondem, respectivamente, às frações grossas $(>0,062 \mathrm{~mm})$ e fina $(\leq 0,062 \mathrm{~mm})$. Com base no reconhecimento dessas propriedades, as unidades deposicionais foram microscopicamente descritas, analisadas e interpretadas, de acordo com Bertran e Texier (1999), Stoops $(2003 ; 2010)$ e Paisani e Pontelli (2012).

\section{Resultados}

\subsection{Propriedades Macroscópicas}

\subsubsection{Paleocanal de Segunda Ordem}

Os materiais do paleocanal de $2^{\mathrm{a}}$ ordem estão expostos em corte da BR-280 na divisa entre os municípios de Palmas (PR) e Água Doce (SC). Trata-se de uma seção estratigráfica transversal ao eixo da paleodrenagem, que fluía para o sistema hidrográfico do rio Iguaçu, cujos materiais se estabeleceram do Último Estadial ao Holoceno Superior (balizado por idades do ${ }^{14} \mathrm{C}$ ) (PAISANI et al., 2013b). O registro estratigráfico está em discordância erosiva com o saprolito de riolito e é composto por horizontes estabelecidos em sete níveis pedoestratigráficos derivados de sedimentos tecnogênico (horizonte $\mathrm{C}$ ), coluvial (2Apb, $2 \mathrm{Cb}, 3 \mathrm{Cb}$ e $4 \mathrm{Cb})$ e aluvial (5Cb, 6 Ab, 6Cgb e 7Cgb). Sinais de pedogênese (traços de raízes, bioturbação e melanização) estão presentes em todos os níveis pedoestratigráficos com diferentes graus de intensidade. Sendo o nível $4 \mathrm{Cb}$ e transições, foco de estudo, uma descrição sucinta dos materiais é apresentada.

O nível $5 \mathrm{Cb}$ corresponde a um conglomerado alu- vial cascalho lamoso maciço com clastos suportados, com limites abruptos, acomodado sobre um pequeno talvegue de um paleocanal. O nível $4 \mathrm{Cb}$ se destaca por apresentar a menor interferência da pedogênese em suas propriedades sedimentológicas. No geral, tem cor 7.5 YR 4/3, textura lama levemente arenosa argilosa (Classificação de Flemming), litorrelíquias (calcedônia, quartzo e fragmentos de riolito) na fração grânulo, distribuídas de forma aleatória e duas lentes centimétricas maciças junto a sua base: uma argilosa e outra de clastos suportados (Figura 2a). Trata-se de um fluxo de terra de alta magnitude, com incorporação de pedorrelíquias de um horizonte $\mathrm{A}$ húmico na base $\mathrm{e}$ de fragmentos da unidade $5 \mathrm{Cb}$, em direção ao centro. Já o nível $3 \mathrm{Cb}$ apresenta-se como linha de pedras descontínuas, formada por cascalho lamoso maciço com matriz suportada (PAISANI et al, 2012; PAISANI et al., 2013b) (Figura 2a). As pedorrelíquias encontradas foram datadas por ${ }^{14} \mathrm{C}$, obtendo idade calibrada de 13.350 a 13.210 AP. para esse nível pedoestratigráfico, o que sugere ter sido gerado na transição Pleistoceno/ Holoceno.

\subsubsection{Rampa de colúvio de fácie proximal}

A rampa de colúvio de fácie proximal, com idade de $8350 \pm 1100 \mathrm{AP}$, datada pelo método de Luminescência opticamente estimulada, corresponde a um conglomerado suportado por matriz silte-arenosa (SHEPARD, 1954), com distribuição aleatória dos clastos no fundo matricial de cor 7.5 YR 6/6. Os sedimentos foram gerados por fluxo de detritos de alta energia durante a transição Holoceno Inferior/Médio e derivam de paleoperfis de intemperismo estabelecidos sobre os arenitos que estruturam o topo e encosta superior da Chapada do Araripe (Formação Exu e Formação Araripina, respectivamente) (CPRM, 2007), com incorporação de blocos de arenito da Formação Exu, que constituíam os depósitos de tálus dispostos na base da escarpa. Tais blocos, oligomíticos, exibem morfologia que varia de anguloso a arredondado e tamanhos diversos, que podem atingir $100 \mathrm{~cm}$ de diâmetro (LIMA,2015). O registro estratigráfico está em discordância erosiva com o saprolito do arenito da Formação Rio da Batateira e é composto por uma única unidade litoestratigráfica. A parte mais próxima do topo, cerca de $30 \mathrm{~cm}$, contém sinais de bioturbação e traços de raízes. 


\subsection{Propriedades Micromorfológicas}

\subsubsection{Paleocanal de Segunda Ordem}

No horizonte $4 \mathrm{Cb}$ da sequência pedoestratigráfica, a micromorfologia foi analisada no centro, topo, base e transições inferior e superior. Empregando o critério da distribuição relativa dos constituintes no horizonte $4 \mathrm{Cb}$, verificou-se o predomínio da categoria porfírica aberta, com ocorrência localizada do padrão enaúlica. Isso mostra que o esqueleto, em menor quantidade, expressa-se descontinuamente em uma matriz plásmica. Com base nas imagens, estima-se que o fundo matricial é composto por uma média aproximada de $7-15 \%$ de esqueleto, $55-70 \%$ de plasma e $22-38 \%$ de poros (Figura 3: a, f, h; Figura 4: k, m).

$\mathrm{O}$ esqueleto é formado por minerais de quartzo ( $\sim 78 \%$ ), calcedônia $(\sim 3 \%)$, magnetita/ilmenita $(\sim 4 \%)$, litorrelíquia ( $\sim 3 \%)$, nódulos litomórficos $(\sim 2 \%)$ e pedomórficos de moderada a forte impregnação $(\sim 10 \%)$ (Figura 3 e 4). A existência desses nódulos pode ser explicada pela remobilização de oxihidróxidos de ferro no perfil do solo do material fonte antes de sua remobilização. Integrando o esqueleto da base da unidade $4 \mathrm{Cb}$, destaca-se a ocorrência de microlascas $(\sim 1 \%)$ e fitólitos ( 1\%) (Figura 3: c, d, d:2, e.1). No geral, o esqueleto apresenta grãos subangulosos a subarredondados, com média a baixa esfericidade, distribuindo-se de forma aleatória no fundo matricial, com ressalva apenas para a parte central, onde ocorre lentes descontínuas de material da unidade $5 \mathrm{Cb}$, cujos grãos estão orientados de forma inclinada e discretas estratificações (Figura 3: g:1); na transição da $5 \mathrm{Cb} / 4 \mathrm{Cb}$, também foi notado discreta estratificação (Figura 3: f). A combinação das frações do esqueleto com o plasma sugere que o material é de natureza pobre a muito pobremente selecionada (Figura 3: a, f; Figura 4: k).

Em relação ao plasma, constatou-se que o mesmo ocorre de forma dispersa no fundo matricial e isoladamente gerando feições intrusivas de preenchimento solto descontínuo a continuo e completo denso, associados a poros cavitários, canais, câmaras e planares (Figura 3: b, c; Figura 4: k, m.1, n.1). A estrutura plásmica com predomínio de orientação indiferenciada $(\sim 70 \%)$ na transição $5 \mathrm{Cb} / 4 \mathrm{Cb}$, no centro da $4 \mathrm{Cb}$ e transição desta com a $3 \mathrm{Cb}$. Localmente, há manchada pontilhada, granoestriada e poroestriada. Já na base e topo da $4 \mathrm{Cb}$, verifica-se uma proporcionalidade entre a orientação indiferenciada ( $\sim 55 \%)$ e birrefringente ( $\sim 5 \%)$. Neste caso, destacando-se a granoestriada, poroestriada e aleatória estriada (Figura 4: i).

Microfeições vinculadas ao processo de depleção e impregnação de oxihidróxidos de ferro são frequentes (Figura 3: a, c, d; Figura 4: j, m, n), enquanto de depleção plásmica são nítidas na base da $4 \mathrm{Cb}$ (Figura 3: e). No geral, são recorrentes microfeições de hipocutãs de impregnação de grão e de poro, com predomínio deste, e em menor proporção os hipocutãs de depleção de grão e de poro, os quais aumentam no topo da $4 \mathrm{Cb}$ (Figura 3: c, e, f; Figura 4: j, n). Neste aspecto, destaca-se o centro da $4 \mathrm{Cb}$, em que estas microfeições aparecem discretamente.

Quasicutãs de impregnação de poro e grão na base e no topo da $4 \mathrm{Cb}$, incluindo neste de depleção de poro, também foram encontrados. São comuns nódulos pedomórficos mátricos e, embora menos frequente, em processo de formação de baixa a moderada impregnação, cuja gênese associa-se ao processo de depleção e acumulação. Muitas vezes, estes nódulos estão sendo fragmentados (Figura 3: c, f, j; Figura 4: i, k.1, m). Aplicando o princípio da distribuição relativa, verifica-se o predomínio das microfeições de impregnação ( $65 \%)$ em relação à depleção ( $\sim 35 \%)$ associada aos poros e esqueleto. Quanto ao plasma, essas microfeições são mais expressivas, por vezes mantendo uma proporcionalidade entre elas, sobretudo na base e transição $4 \mathrm{Cb} / 3 \mathrm{Cb}$. Neste contexto, o centro da $4 \mathrm{Cb}$ se destaca por não exibir feições significativas de depleção e impregnação, as quais ocorrem de forma localizada (Figura 3: g, g.1).

No geral, o horizonte $4 \mathrm{Cb}$ não mostra uma organização pédica (Figura 3: h; Figura 4: k). Quando ocorre é pontual e do tipo microagregados, em blocos subangulares e planares (Figura 3: a, a:1), variando de parcialmente acomodado a acomodado, moderadamente a altamente desenvolvido. Todavia, a transição 5Cb/4Cb (Figura 3: f, f.1) e base da 4CB destacam-se pela maior ocorrência de peds formados. Convém enfatizar, também, a forte tendência a organização pédica constatada na transição $4 \mathrm{Cb} / 3 \mathrm{Cb}$ (Figura 4: m). Neste setor, sobretudo na base, nota-se a assinatura de peds microagregados granulares formados, de fraco a moderado grau de desenvolvimento, assim como em blocos subangulares e prismoidais, de grau fraco, não acomodados a parcialmente acomodados. Além destes, observa uma propensão à formação de peds granulares. 

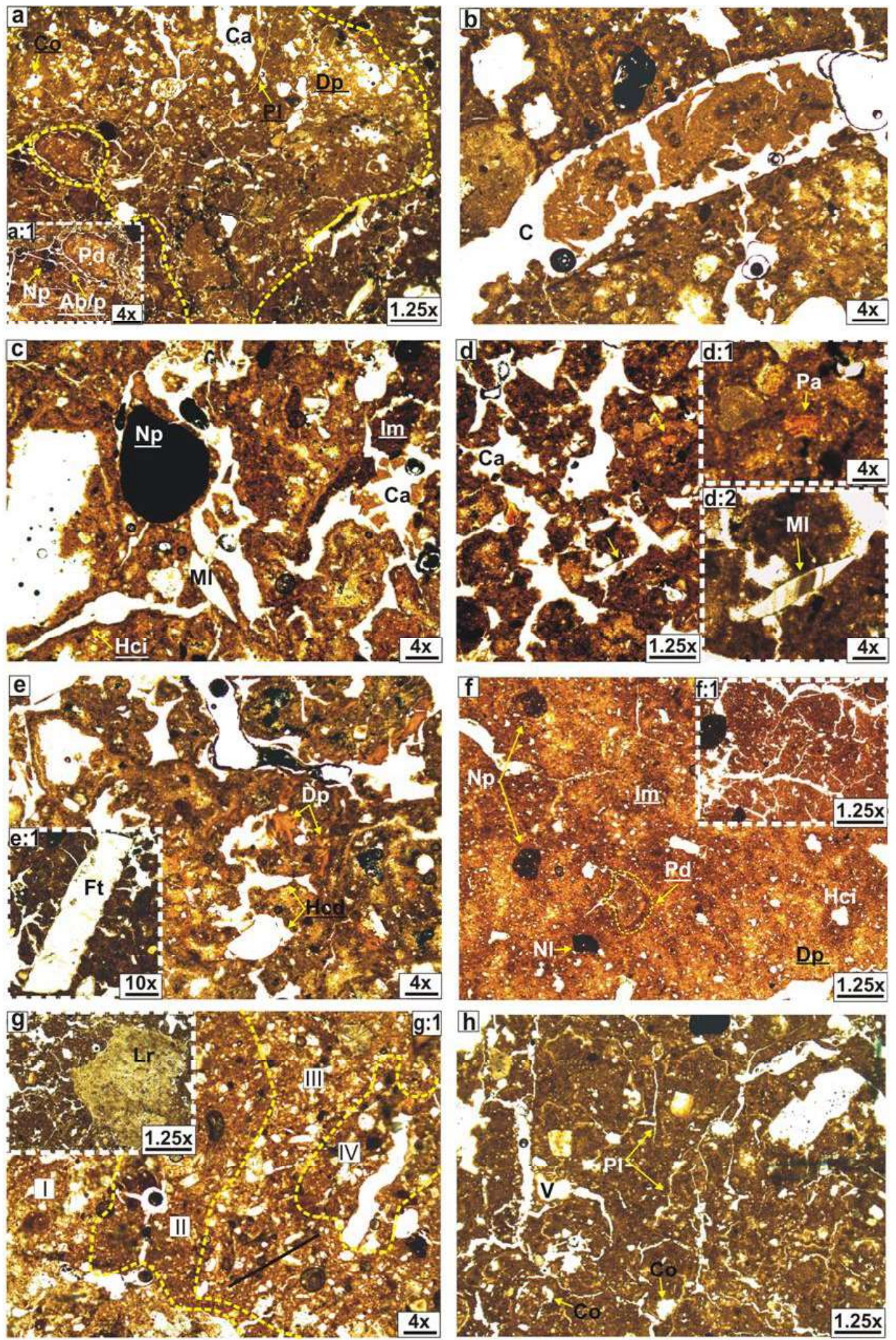

Figura 3 - Imagens micrográficas da Seção pedoestratigráfica de paleofundo de vale de segunda ordem (HS1) a) Base - Porfíica aberta; poros composto (Co), cavitários (Ca) e planares (Pl); área com deplę̧ão (Dp); a:1) Detalhe de pedorrelíquia (Pd), nódulo pedomórfico (Np) sendo fragmentado, agregado em blocos subangulares a planares (Ab/p). b) Poro canal (c) com preenchimento denso; c) Nódulo pedomórfico, impregnação mátrica (Im), microlasca (Ml), poros cavitários e hipocutãs de impregnação (Hci); d) Poros cavitários sendo abertos, microlasca e pápula (Pa). d:1) Detalhe da pápula; d:1) Detalhe da microlasca. e) Depleção (Dp) e hipocutã de depleção (Hcd); e:1) Detalhe de um fitólito elongate. f) Transição inferior (5Cb/4Cb) - Nódulo pedomórfico sindeposicional, impregnação mátrica, pedorrelíquia e nódulo litomórfico (Nl); f:1) visão da aparente pedalidade. g) Centro - Litorrelíquia (Lr); g:1) Discretas microestratificações mostrando orientação do esqueleto. h) Topo - Porfirica aberta, poro vesícula (v), planar e composto. 

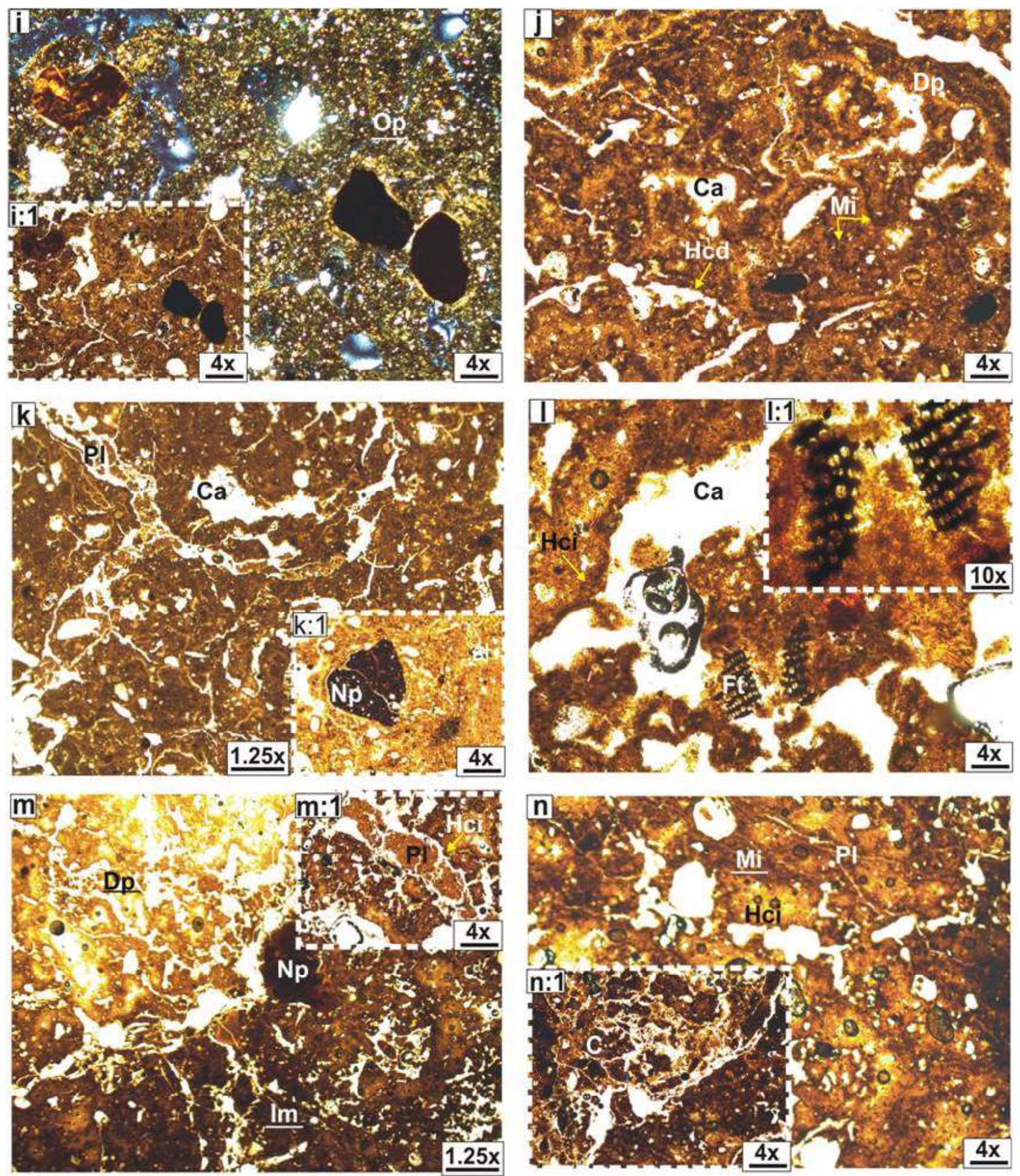

Figura 4 - Imagens micrográficas da seção pedoestratigráfica HS1. i) Topo - orientação plásmica (Op); i:1) a mesma imagem sem luz polarizada. j) migração de oxihidróxido de ferro (Mi), depleção (Dp), poros cavitários e hipocutãs de depleção. $k$ ) poros cavitários e planares com preenchimento solto descontínuo; $k: 1)$ nódulo pedomórfico sindeposicional sendo fragmentado. l) Transição Superior (4Cb/3Cb) fitólito carbonizado e poro cavitário; l:1) detalhe do fitólito. $m$ ) depleção (Dp), impregnação mátrica e nódulo pedomófico; m:1) detalhe de poros planares com preenchimento denso e hipocutã de impregnação; $n$ ) poros planares sendo abertos nas áreas preferenciais de migração de oxihidróxidos de ferro, e hipocutãs de impregnação; n:1) poro canal com preenchimento solto denso. 
Feições intrusivas do tipo pápula e pedorrelíquia de agregado foram encontradas compondo o fundo matricial do horizonte 4Cb (Figura 3: d, d.1, f). As pápulas são comuns em todo o horizonte, sendo em menor quantidade na transição $5 \mathrm{Cb} / 4 \mathrm{Cb}$ e na parte central da $4 \mathrm{Cb}$, onde ocorrem fragmentos de clastos suportados incorporados no movimento de massa (Figura 3: g). As pedorrelíquias foram encontradas apenas na base da $4 \mathrm{Cb}$ e na transição inferior. Destaca-se ainda a presença isolada de um poro com preenchimento denso em gel na transição $5 \mathrm{Cb} / 4 \mathrm{Cb}$, um cutã e um fitólito carbonizado na transição $4 \mathrm{Cb} / 3 \mathrm{Cb}$ (Figura 4: 1).

Quanto aos poros, na transição da $5 \mathrm{Cb} / 4 \mathrm{Cb}$, há um predomínio de planares ( $73 \%)$ em relação aos cavitários ( $\sim 7 \%)$ e os compostos ( $20 \%)$. Na base da $4 \mathrm{Cb}$, onde ocorrem as lentes de pedorrelíquias do horizonte $\mathrm{A}$ húmico, os poros planares $(\sim 46)$ e compostos $(\sim 30)$ são os predominantes (Figura 3: a; c; h; Figura 4: k; n). Os planares são comuns na base com espessura fina, diminuindo em quantidade em direção ao topo e tornando-se mais espessos. Os compostos estão dispersos no plasma. Ainda foram encontrados canais ( 3\%) (Figura 3: b), câmara ( $1 \%$ ), vesícula ( $1 \%$ ) (Figura $3:$ h) e cavitários $(\sim 19 \%)$. No centro da $4 \mathrm{Cb}$, a porosidade é similar à base, visto o domínio dos poros planares $(\sim 88 \%)$, intercalado por cavitários $(\sim 7 \%)$ e compostos $(\sim 5 \%)$. No topo da $4 \mathrm{Cb}$, a porosidade varia de poros complexos $(\sim 3 \%)$, canais $(\sim 3 \%)$, vesícula $(\sim 2 \%)$, cavitários $(\sim 35 \%)$, planares $(\sim 45 \%)$ e composto $(\sim 10 \%)$. Na transição $4 \mathrm{Cb} / 3 \mathrm{Cb}$, observa-se o aumento dos poros compostos ( 45\%) e uma diminuição dos planares ( 22\%), acompanhados de cavitários $(\sim 25 \%)$, canais $(\sim 5 \%)$ e complexos $(\sim 3 \%)$. Muitos poros planares e cavitários estão sendo abertos, sobretudo na transição $5 \mathrm{Cb} / 4 \mathrm{Cb}$ e $4 \mathrm{Cb} / 3 \mathrm{Cb}$, respectivamente.

\subsubsection{Rampa de colúvio de fácie proximal (CSM-C)}

A distribuição relativa dos constituintes demonstra similaridade com a descrição macroscópica. Assume padrão porfírica aberta, localmente fechada e enaúlica, refletindo a ocorrência menos frequente do esqueleto disposto em uma matriz plásmica. Com base nas imagens, estima-se que o fundo matricial é composto por ( $25 \%$ ) de esqueleto, ( $60 \%)$ de plasma e $(\sim 15 \%)$ de poros (Figura 5: a, b).

$\mathrm{O}$ esqueleto é constituído majoritariamente por quartzo ( $\sim 88 \%$ ), seguido de litorrelíquias - relicto sedimentar - $(\sim 2 \%)$ e de nódulos tanto pedomórfico $(\sim 8 \%)$ como litomórfico $(\sim 2 \%)$ de moderada a forte impreg- nação (Figura 5: e, f, g), os quais denunciam a presença de oxihidróxidos de ferro provavelmente vinculado à pedogênese do material fonte. Por vezes, os nódulos pedomórficos encontram-se fragmentados, refletindo o desmantelamento de sua estrutura. Com base nos dados granulométricos, predomina a fração areia média a muito fina, muito angular a sub-angular, de média a alta esfericidade, sendo esta propriedade um reflexo do material parental de formação arenítica (LIMA, 2015). O esqueleto encontra-se distribuído de forma aleatória, com setores organizados em estratificações cruzadas de diferentes direções. A combinação das frações do esqueleto com o plasma sugere que o material é de natureza pobre a muito pobremente selecionado (Figura 5: a).

Em relação ao plasma desta unidade litoestratigráfica, constatou-se que o mesmo ocorre de forma dispersa no fundo matricial e isoladamente gerando feições intrusivas de preenchimento solto descontínuo e completo denso, associadas, respectivamente, a poros cavitários e canais (Figura 5: b). O plasma exibe estrutura plásmica com predomínio de orientação indiferenciada, possivelmente em decorrência da forte impregnação do plasma por oxihidróxido de ferro (Figura 5: g, i; Figura 6: k), e, localmente, orientação birrefringente do tipo granoestriada, poroestriada, aleatória e crescente estriada (Figura 5: h, j; Figura 6: 1). Registram-se nódulos pedomórficos mátricos e, embora menos frequente, em processo de formação de baixa a moderada impregnação, cuja gênese associa-se ao processo de depleção e acumulação (Figura 5: d).

Microfeições vinculadas ao processo de depleção e impregnação de oxihidróxidos de ferro e argila são comuns (Figura 5: b, c, d, g, h; Figura 6: i, k). Assim sendo, foram reconhecidas as seguintes microfeições: hipocutãs de depleção de poro e grão; hipocutãs de impregnação de grão e de poro, sendo estes predominantes; quasicutãs de impregnação de poro e de grão; microfeição de depleção e de impregnação plásmica, por vezes associada à geração de poros cavitários e pequenos planares; e feições de revestimento. Na base da lâmina que exemplifica os materiais da unidade, ocorre um aumento de microfeição de depleção com setores exibindo coloração clara intercalada por escura. Já no topo da lâmina da referida unidade constata-se o aumento significativo das microfeições de impregnação mátrica. Com base no princípio da DRC, estima-se um predomínio de feições de impregnação mátrica $(\sim 55 \%) \mathrm{em}$ relação à depleção ( $45 \%)$, esta sendo mais significativa no fundo matricial do que vinculada aos poros e grãos. 

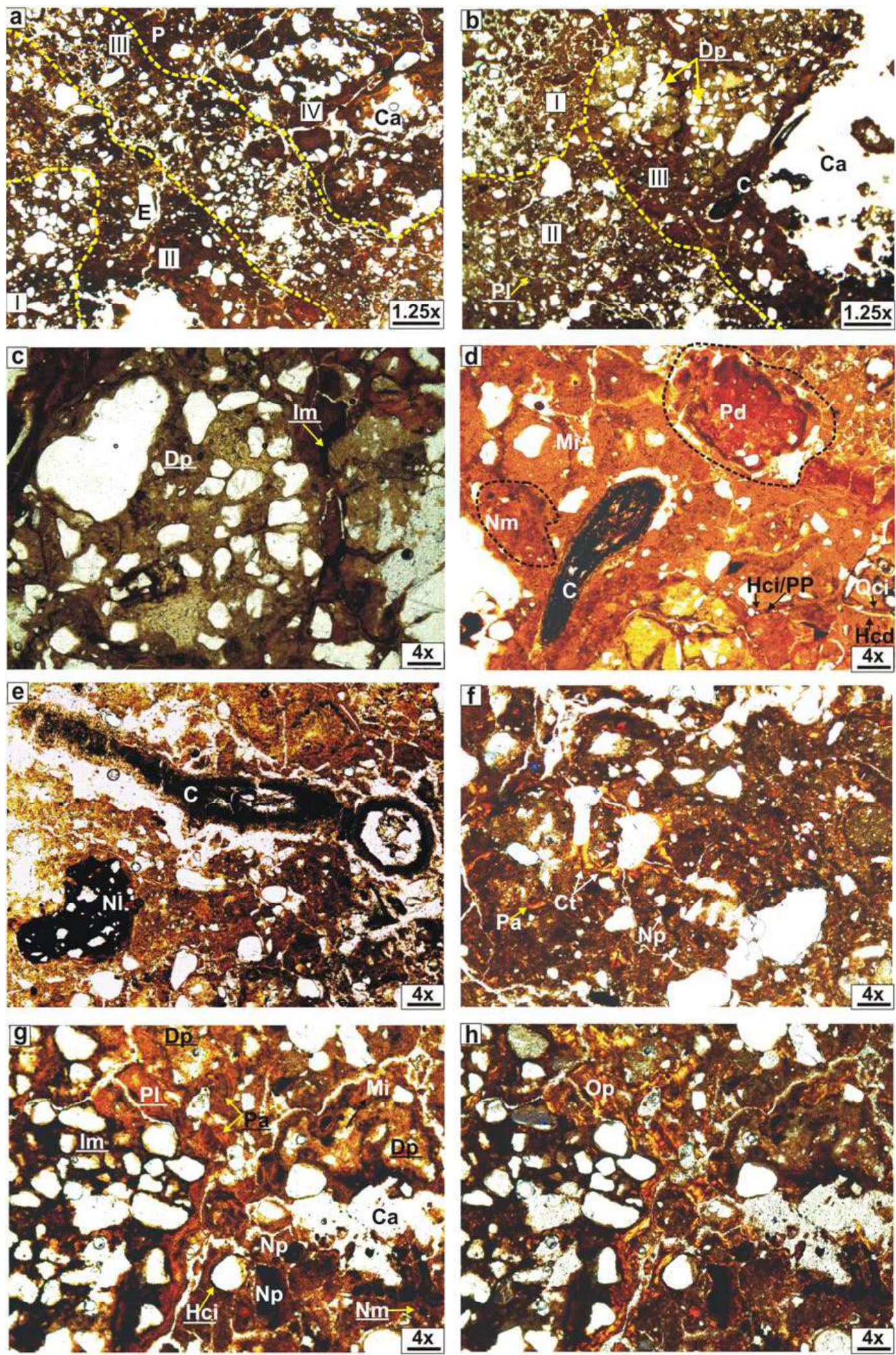

Figura 5 - Imagens micrográficas da Seção litoestratigráfica de fácie proximal de rampa de colúvio (CSM-C). a) microestratificações e DRC porfírica aberta, localmente fechada. E - esqueleto; P - plasma; b) microestratificações, poros cavitários, canal preenchido por matéria orgânica e planares; áreas com depleção (Dp); c) detalhe das áreas com depleção e impregnação mátrica; d) detalhe do poro canal com matéria orgânica, nódulos mátricos (Nm), migração de oxihidróxido de ferro, hipocutãs de impregnação, poros planares com preenchimento solto descontínuo (Pp), quasicutãs de impregnação (Qci), hipocutã de depleção e pedorrelíquia; e) canal com preenchimento e nódulo litomórfico; f) cutãs típicos (Ct), pápulas e nódulos pedomórficos; g) depleção mátrica, poros planares e cavitário, impregnação mátrica, pápula, migração de oxihidroxido de ferro, nódulos mátricos (Nm), nódulos pedomórficos e hipocutãs de impregnação; $h$ ) orientação plásmica. 

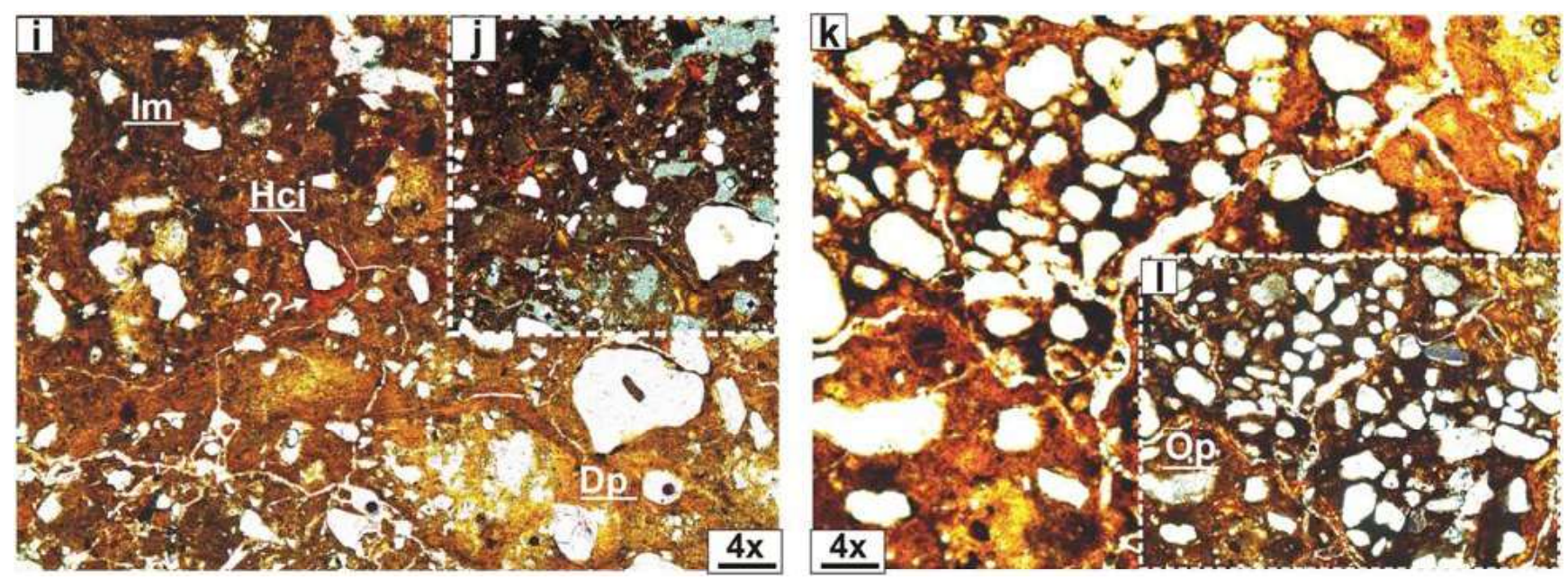

Figura 6 - Imagens micrográficas da Seção CSM-C. i) Depleção e impregnação mátrica; hipocutãs de impregnação; j) orientação plásmica; k) concentração do esqueleto associada à impregnação por oxihidróxido de ferro; l) orientação plásmica.

No geral, o plasma é apédico (Figura 5: a), com ocorrência pontual de microagregados granulares acomodados a parcialmente acomodados, os quais estão associados aos setores com padrão enaúlica e alguns agregados em blocos subangulares, não acomodados a parcialmente acomodados. Ainda compondo o fundo matricial, pedofeições fragmentadas (pápulas) e pedorrelíquia foram identificadas, aquelas em maior quantidade, e esta com um único registro (Figura 5: d, g, h).

Quanto aos poros, variam de compostos $(\sim 16 \%)$, cavitários $(\sim 54 \%)$, planares $(\sim 25 \%)$, canais $(\sim 4 \%)$ e câmara ( 1\%) (Figura 5: b, e, g). Os compostos estão associados à microestrutura intergranular; os cavitários distribuem-se no fundo matricial, por vezes exibindo aspecto de desmonte e ligados a poros planares; os planares, geralmente muito finos, encontram-se cortando áreas de forte impregnação sem evidência de preenchimento e, frequentemente, articulado a grãos e poros cavitários (Figura 5: a, h; Figura 6: i, k).; ocasionalmente, os poros canais apresentam-se preenchidos por matéria orgânica em estágio de decomposição (Figura 5: d, e). Vinculado aos poros, destaca-se ainda a presença de cutãs (Figura 5: f).

\subsection{Discussão dos resultados}

A análise micromorfológica em colúvio permite caracterizar os materiais quanto à área fonte, usando da identificação de microfeições herdadas, os processos deposicionais envolvidos durante a sedimentação e as transformações pós-deposicionais motivadas pela retomada da pedogênese. Assim encadeadas, tais in- formações fornecem elementos-chave que auxiliam na determinação da assinatura estratigráfica dos depósitos e das condições paleoambientais de sua formação. À vista disso, a discussão dos dados segue essa ordem de concatenação.

\subsubsection{Microfeições herdadas do material fonte}

Embora as seções sejam de áreas e materiais de origens diferentes, a análise micromorfológica sugere que os constituintes do esqueleto e plasma refletem as características sedimentológicas de formação. Nos materiais coluviais da Seção Pedoestratigráfica HS1, foram encontradas microfeições herdadas como grãos orientados com certo grau de inclinação, estratificações e plasma com forte impregnação de oxihidróxidos de ferro. Discretas estratificações e forte impregnação por oxihidróxidos de ferro também foram encontradas na Seção Litoestratigráfica Rampa de colúvio de fácie proximal (CSM-C). A manutenção de laminações evidencia a baixa atuação de processos pós-deposicionais e/ou pedogenético na reorganização interna dos materiais coluviais.

Apesar de não ser comum, litorrelíquias estão presentes na composição do esqueleto da base à transição superior da $4 \mathrm{Cb}$ e na seção CSM-C. Inclui-se também, em ambas as seções, os nódulos litomórficos, sendo estes, no horizonte $4 \mathrm{Cb}$, restritos à base e centro. Aplicando o raciocínio de Paisani e Pontelli (2012), as litorrelíquias e os nódulos litomórficos são indicadores de mistura de materiais envolvendo o horizonte $\mathrm{C}$, induzindo a pensar que o movimento de massa excedeu o limite do solum em profundidade. Esta informação é 
coerente com os materiais, uma vez que os componentes da base e centro da $4 \mathrm{Cb}$ exibem, respectivamente, aspecto de um horizonte $\mathrm{A}$ húmico e fragmentos do conglomerado aluvial da unidade $5 \mathrm{Cb}$, remobilizado durante o fluxo. O mesmo ocorre com a seção CSM-C, quando macroscopicamente se verifica um fluxo de alta energia com incorporação de blocos de dimensão superior a $100 \mathrm{~cm}$.

Os nódulos pedomórficos de forte impregnação são frequentes no horizonte $4 \mathrm{Cb}$ e na seção CSM-C. Conforme Paisani e Pontelli (2012), este tipo de nódulo, reconhecível apenas em escala microscópica, mostra que o processo de nodulação no paleoperfil de intemperismo era incipiente. Reflexionando sobre isso, verifica-se que esta assertiva alinha-se com os dados das seções, uma vez que não revelaram, em escala macroscópica, a presença de nódulos. Outras microfeições ligadas a herança do material parental foram encontradas tanto no horizonte $4 \mathrm{Cb}$ como na seção CSM-C: i) forte impregnação do fundo matricial por oxihidróxidos de ferro; ii) embora limitada, pedorrelíquias de agregados em blocos subangulares de paleohorizontes na base da $4 \mathrm{Cb}$ e na seção CSM-C, as quais foram preservadas durante o processo de erosão, transporte e deposição; iii) e presença frequente de fragmentos de cutãs (pápulas) em ambas as seções. Estas feições intrusivas são elementos relictuais de um material pedológico com acumulações plásmicas que sofreu transporte, conservando seu registro embora fragmentado. A simultaneidade dessas microfeições confirma a existência de uma cobertura pedológica anterior, que foi obliterada pela ação da morfogênese, a qual era rica em oxihidróxido de ferro. Além disso, sinaliza que de fato os depósitos resultaram de uma mistura de horizontes envolvendo o $\mathrm{C}$ de paleoperfis de intemperismo (PAISANI e GEREMIAS, 2010; PAISANI e PONTELLI, 2012).

Além de todos esses registros que compõem a assinatura estratigráfica do material parental, dois tipos de microfeições, imersas no plasma do horizonte $4 \mathrm{Cb}$, chamaram a atenção: i) A distinção de duas microlascas na base, cuja ocorrência alinha-se com as pedorrelíquias do horizonte A húmico, validadas por Paisani et al (2012), as quais provavelmente estiveram expostas à superfície antes do movimento de massa. Esta informação auxilia no reconhecimento de paleosuperfícies e de áreas com indícios de ocupação humana pretérita, reforçando a importância dos depósitos quaternários para a Arqueologia. ii) A identificação de um fitólito
Elongate, também na base da $4 \mathrm{Cb}$, bem preservado pertencente ao grupo das gramíneas (maioria das Poaceae C4) (RAITZ, 2012), o qual está de acordo com a análise fitolítica de Paisani et al (2013b), em que constataram a presença da vegetação de Campo Cerrado. iii) A presença de fitólito carbonizado na transição da $4 \mathrm{Cb} / 3 \mathrm{Cb}$, o qual aponta para uma paleosuperfície exposta a paleoincêndios, cuja origem poder ser tanto natural quanto motivada pela atividade de paleoíndios. Até então, são poucos os fitólitos observados em seções finas (STOOPS et al, 2010).

\subsubsection{Processos deposicionais}

De forma geral, os processos deposicionais mantém uma estreita relação com as propriedades sedimentológicas de origem. Neste sentido, a análise micromorfológica associada à granulometria mostrou similaridades entre as seções. Tanto o horizonte $4 \mathrm{Cb}$ como a seção CSM-C são constituídos pela combinação de esqueleto e plasma, de natureza pobre a muito pobremente selecionada, predominantemente organizados na categoria porfírica aberta. Esta categoria aliada a baixa seleção dos constituintes, com estrutura maciça, sugere depósitos gerados por fluxos de detritos, na seção CSM-C, e de terra, na unidade $4 \mathrm{Cb}$ da seção HS1, os quais macroscopicamente foram reconhecidos por Lima (2015) e Paisani et al, (2012).

Igualmente, a DRC porfirica aberta exprime o caráter viscoso dos fluxos durante o movimento de massa (BERTRAN e TEXIER, 1999), assim como sinaliza que tais derivaram de paleoperfis com relativa quantidade de finos inferiores a silte grosso. Isto é importante, mormente quando se investiga a seção CSM-C, cuja composição mineralógica e granulométrica tem sua gênese ligada a paleoperfis derivados de rocha arenítica. Evidências localizadas da categoria enaúlica no horizonte 4Cb e na seção CSM-C estão vinculadas ao retrabalhamento pelos organismos gerando pedotúbulos e desmonte, por vezes incipiente, dos poros cavitários. Isto, portanto, não é suficiente para apontar mudanças reológicas dos fluxos.

Embora apresentem estrutura maciça com aspecto caótico do esqueleto no plasma, alguns setores com discretas orientações foram identificados. Na transição $5 \mathrm{Cb} / 4 \mathrm{Cb}$, o esqueleto exibe sutil orientação com certo grau de inclinação, tornando-se mais nítido no centro da $4 \mathrm{Cb}$. Ainda que os materiais de estudo sejam de origem 
coluvial, observa-se que tal comportamento é coerente com o material da 5Cb, reconhecido por Paisani et al (2012) como conglomerado aluvial formado em um paleoeixo de drenagem. Isso é possível visto que a $5 \mathrm{Cb}$ marca o limite inferior da $4 \mathrm{Cb}$, mantendo uma zona de contato. Não obstante, serve para confirmar que os fragmentos de conglomerado encontrado na parte central da $4 \mathrm{Cb}$ têm sua gênese ligada ao depósito da $5 \mathrm{Cb}$. Já na seção CSM-C, ocorrem orientações pontuais do tipo bandada. Todavia, essa organização não é o bastante para sugerir mudança reológica do fluxo, a qual pode ser apenas um reflexo da acomodação durante e imediatamente após a deposição.

Apenas na base do horizonte $4 \mathrm{Cb}$, registrou-se a presença de vesícula. De acordo com Bertran e Texier (1999), esse tipo de poro é formado por bolhas aprisionadas na matriz durante o transporte. Quando presente em depósitos, indica que foram formados por fluxos liquefeitos. Somam-se aos processos deposicionais do horizonte $4 \mathrm{Cb}$ e da seção CSM-C, as microfeições de nódulos mátricos de moderada a forte impregnação e áreas expressivas de impregnação de oxihidróxido de ferro, as quais, por vezes, estão cortadas por poros livres de preenchimentos. Tais aspectos demonstram o significativo conteúdo de oxihidróxido de ferro livre na cobertura pedológica que forneceu material, assim como a existência de água, definindo áreas preferenciais de impregnação com formação de nódulos, aqui interpretados como sindeposicionais. Assim, o conjunto dessas informações micromorfológicas cambiadas pela análise macroscópica possibilita aventar que os depósitos de ambas as seções foram originados por deslizamentos, cujos fluxos de detritos na seção CSM-C e de terra na unidade $4 \mathrm{Cb}$ continham elevado teor de sedimentos, em que a componente água esteve presente comandando o processo deposicional.

\subsubsection{Transformações pós-deposicionais}

A presença e/ou grau de pedalidade é o primeiro aspecto usado para reflexionar sobre a intensidade das transformações sofridas por um material após sua deposição. Quanto a esse aspecto, a análise micromorfológica dos depósitos permitiu aferir que os mesmos apresentam-se predominantemente apédicos, com ocorrência localizada de feições pédicas do tipo microagregados, em blocos subangulares e planares, de moderado grau de desenvolvimento e parcialmente acomodados a acomodados, tanto na seção CSM-C como no horizonte $4 \mathrm{Cb}$. Tal constatação mostra que as transformações pós-deposicionais encontram-se em estágio inicial, e que não foram capazes de reorganizar o material como se presume pela intervenção da pedogênese (PAISANI e PONTELLI, 2012).

Acerca do grau de pedalidade, duas observações são convenientes. A primeira diz respeito à tendência a organização pédica na transição $4 \mathrm{Cb} / 3 \mathrm{Cb}$. Esta fisionomia associada ao desmantelamento do material e ocorrência de pedotúbulos, e ainda à identificação de fitólito queimado, induz pensar que este material esteve estruturando a superfície, sendo possivelmente interrompida pela ação erosiva com retrabalhamento e formação da unidade sobreposta. Segundo, a aparente pedalidade observada na transição $5 \mathrm{Cb} / 4 \mathrm{Cb}$, vinculada a expressiva porosidade, pode ser uma resposta às condições de pressão pós soterramento, e não a uma reorganização de caráter pedogenético, visto que, em escala de detalhe, o material contém áreas de circulação de água com abertura incipiente de poros planares sem preenchimento e sem feições de acumulações que indiquem pedogênese. Sobre porosidade, Bertran e Texier (1999) chamaram a atenção de que deve ser tomado com cuidado, pois é uma característica muito instável, limitando seu uso no diagnóstico de processos pós-deposicionais. Embora incipientes, as transformações pós-deposicionais, que podem ter começado imediatamente após a deposição, sinalizam que a água tem sido o principal fator de transformação e que a mesma esteve presente desde o processo deposicional no horizonte $4 \mathrm{Cb}$ e na seção CSM-C. O reconhecimento de nódulos mátricos sindeposicionais e zonas de migração corroboram esta assertiva.

As microfeições de impregnação e depleção aliadas aos hipocutãs e quasicutãs de impregnação, comuns ao horizonte $4 \mathrm{Cb}$ e a seção CSM-C, são elementos que sugerem a continuidade da água pela infiltração dos eventos pluviométricos posteriores. De acordo com Lendbo et al (2010), em períodos com saturação prolongada (dias a semanas), simultaneamente poderão ocorrer pedofeições de impregnação e de depleção. Por outro lado, para que o processo de nodulação se desenvolva é necessário que o período de saturação seja curto ou que nem aconteça e que os materiais estejam sob condições de boa drenagem com relativa umidade e aeração.

Analisando o acúmulo dessas microfeições associadas à migração e acumulação de ferro, formando 
nódulos, e marcadas feições de depleção, pode-se pensar que o horizonte $4 \mathrm{Cb}$ e a seção CSM-C passam por momentos de saturação, com relativa duração, intercalada por momentos não saturados, provavelmente vinculados a estações bem definidas com relativa umidade e disponibilidade de água. A essa circulação de água soma-se o desmantelamento dos materiais com abertura sucessiva de poros planares, cortando nódulos de forte impregnação, assim como a abertura de cavitários, composto e complexos. Este comportamento revela que o plasma, por perda sucessiva e acumulação de oxihidróxido e de argila, encontra-se reorganizando internamente conforme aumenta ou diminui a circulação de água. A tendência evolutiva é que as microfeições herdadas e sindeposicionais sejam anuladas à medida que os processos deposicionais se intensifiquem, os quais são dependentes de um longo período de estabilidade pedogenética.

A continuidade da circulação de água internamente nos materiais é também notada pelo padrão de orientação plásmica majoritariamente associada ao esqueleto e aos poros. Neste aspecto, destacam-se a base e o topo da $4 \mathrm{Cb}$ pela presença proporcional tanto de plasma com orientação indiferenciada quanto orientada. Enquanto a orientação indiferenciada tem relação com o teor de oxihidróxido de ferro e de matéria orgânica, a orientada reflete a reorganização dos materiais, com significativa abertura de poros planares e cavitários. A presença de pedotúbulos no topo da $4 \mathrm{Cb}$ sugere que, em fase anterior, esteve diretamente exposta aos processo hidrológicos superficiais e a atividade biológica.

Feições de depleção plásmica contíguas a corredores de migração de ferro, por vezes cortados por superimposição de poros planares, ocorrem tanto na base do 4Cb como na CSM-C. Estas feições apresentam-se fortemente orientadas e os poros associados não exibem sinais de preenchimentos. Observando os poros planares e comparando com os reflexos dos argilominerais encontrados no $4 \mathrm{Cb}$ por Paisani et al (2015), em que foi identificado vermiculita $(2: 1)$, pode-se pensar que a presença deles, na maioria livre de preenchimento e sem sobreposição de poros, é mais um reflexo natural às propriedades físicas deste argilomineral ao comportamento hidrológico do material. O mesmo raciocínio se aplica a seção CSM-C, embora o argilomineral ilita (2:1) não tenha o mesmo comportamento expansivo/ compressivo da vermiculita.

\section{Conclusões}

As propriedades micromorfológicas encontradas serviram de base para identificar os processos envolvidos e as condições ambientais de formação do horizonte $4 \mathrm{Cb}$ e da seção CSM-C, como pretendido no objetivo. A unidade $4 \mathrm{Cb}$ da seção HS1 trouxe chaves interpretativas processuais e pós-deposicionais de proeminente significado paleoambiental. Os dados mostraram que o nível $4 \mathrm{Cb}$, embora aparentemente homogêneo, não foi gerado por um único fluxo, e que a umidade comandou a evolução dos processos. A hipótese de vários fluxos, provavelmente de baixa intensidade, baseia-se na concentração de pedorrelíquia na base e na presença restrita de fragmento de um conglomerado clasto suportado no centro. Caso fosse um único episódio deposicional, as pedorrelíquias teriam sido incorporadas homogeneamente ao longo de todo o fluxo, e/ou sinais micromorfológicos de migração interna teriam sido encontrados. A própria disposição das pedorrelíquias imersas em uma matriz reforça essa assertiva. $\mathrm{O}$ mesmo raciocínio se aplica ao fragmento de conglomerado, o qual sugere um novo fluxo soterrando o material subjacente. Outro aspecto importante é observado quando se compara as microfeições da base com o topo da $4 \mathrm{Cb}$. $\mathrm{Na}$ base, há muito mais feições hidromórficas do que no topo. Este dado sinaliza que, embora colmatado, o paleoeixo de drenagem continuou orientando os fluxos subsuperficiais posteriores, possivelmente até o Holoceno Superior.

Na seção CSM-C, as microfeições encontradas apresentam similaridades com as verificadas na unidade $4 \mathrm{Cb}$. Sendo um fluxo de detrito de fácies proximal sem vinculação com colmatação de paleoeixo de drenagem, as imagens micrográficas revelaram um acúmulo de feições hidromórficas associadas a áreas de migração e impregnação por oxihidróxido de ferro, com abertura de poros cavitários, nódulos tanto ligados aos processos sindeposicionais como pós-deposicionais e um plasma com evidências de reorganização interna, observadas pela forte orientação birrefringente. O conjunto dessas microfeições, em especial as hidromórficas e de impregnação, correlaciona-se com o comportamento da base da $4 \mathrm{Cb}$, responsável pelo preenchimento do paleoeixo de drenagem. Essa informação é relevante, pois denuncia o papel da água na reorganização interna do material da seção CSM-C. 
Comparando a unidade $4 \mathrm{Cb}$, a qual foi gerada em uma situação ambiental de mais seco para mais úmido (Paisani et al, 2012; 2013b), com a seção CSM-C, pode-se concluir que: I) a componente água esteve presente nas unidades coluviais, tanto durante como posterior ao evento deposicional. Isto demonstra que ambas tem importante significado paleoambiental, sobretudo para o sul do Ceará, que regionalmente encontra-se inserido no contexto semiárido; II) as evidências micromorfológicas comuns de depleção e migração de oxihidróxido de ferro permitem apontar que as condições paleoambientais de formação dos colúvios foram similares, gerados na transição de um ambiente mais seco para mais úmido. De acordo com o modelo de Knox (1972), esse momento é acompanhado de forte instabilidade morfogenética condicionada pela reorganização dos sistemas ambientais às mudanças ou oscilações de um padrão climático vigente, antes de sua adequação. Ao se adequar, o ambiente retoma as condições de estabilidade pedogenética, as quais são necessárias à evolução das coberturas superficiais que revestem a paisagem; III) o acúmulo das microfeições hidromórficas e de migração dos oxihidróxidos de ferro com aberturas de poros testemunha a continuidade da água no sistema. Com isso, pode-se pensar que o processo de reumidificação reconhecido para o entorno do Planalto da Borborema no Holoceno Inferior por Corrêa (2001) e Tavares (2015) também ocorreu no setor Norte/Nordeste do Planalto Sedimentar do Araripe, estendendo-se à modernidade.

Por fim, os resultados encontrados ratificam a potencialidade dessa técnica em estudos, que procuram entender a dinâmica paleoambiental de um ambiente de encosta. Sendo a carência de trabalhos dessa ordem um fator limitante às possibilidades interpretativas, amplia-se a necessidade de pesquisas futuras que possam agregar feições diagnósticas importantes para o reconhecimento de processos de encosta e das condições ambientais de formação. Deste modo, as informações aqui produzidas somam-se às poucas existentes sobre micromorfologia em ambiente de encosta, o que por si já acusa a sua contribuição para os estudos com ênfase em reconstrução paleoambiental no Quaternário Superior.

\section{Agradecimentos}

À CAPES, pela bolsa de Pós-Doutorado (Projeto 144/2012); ao CNPq (Proc. 300530/2012-9), pelo apoio financeiro; e ao Programa de Pós-Graduação em Ge- ografia - UNIOESTE/Campus Francisco Beltrão/PR, pela viabilização do estágio.

\section{Referências Bibliográficas}

ANDRADE, G. O. A superfície de aplainamento pliocênica do Nordeste do Brasil. Universidade do Recife, Diretoria Acad. Da Faculdade de Filosofia, 1958, 44 p.

ANDRADE-LIMA, D. Vegetação. In: IBGE. Atlas Nacional do Brasil. Rio de Janeiro: Conselho Nacional de Geografia, 1966.

ANDRADE, G. O; CALDAS LINS, R. Introdução à morfoclimatologia do Nordeste do Brasil. Arqu. Inst. Cienc. da Terra, Recife, v.3, n.4, p.17-27, 1963

ARAUJO, A. G. M; STRAUSS, A. M; FEATHERS, J. K; PAISANI, J. C; SCHRAGE, T. J. Paleoindian Open-Air Sites in Tropical Settings: A Case Study in Formation Processes, Dating Methods, and Paleoenvironmental Models in Central Brazil. Geoarchaeology (New York. Print), v. 28, p. 195-220, 2013.

BARRETO, A. M. F. Interpretação Paleoambiental do Sistema de Dunas Fixadas do Médio São Francisco, Bahia. 1996. 174 f. Tese (Doutorado em Geologia) - Universidade de São Paulo, SP, 1996.

BEHLING, H; ARZ, H. W; PÄTZOLD, J; WEFER, G. Late Quaternary vegetational and climatic dynamics in northeastern Brazil, inferences from marine core GeoB 3104-1. Quaternary Science Reviews, v.19, p.981-994, 2000.

BEHLING, H; PILLAR, V. D. P; OLÓCI, L; BAUERMANN, S. G. Late quaternary Araucaria forest, grassland (campos), fire and limate dynamics, studied by high-resolution pollen, charcoal and multivariate analysis of the Cambará do Sul core in southern Brazil. Palaeogeography, Palaeoclimatology, Palaeoecology, v.203, p.277-297, 2004.

BEZERRA, F. H. R; NEVES, B. B. B; CORREA, A. C. de B; BARRETO, A. M. F; SUGUIO, K. Late Pleistocene tectonicgeomorphological development within a passive margin - The Cariatá trough, northeastern Brazil. Geomorphology, v.97. p.555-582, 2008.

BERTRAN, P; TEXIER, J. P. Facies and microfacies of slope deposits. Catena, v.35, p.99-21, 1999.

BIGARELLA, J. J; MOUSINHO, M. R; SILVA, J. X. da. Contribuições a respeito evolução das vertentes. Boletim Paranaense de Geografia, n. 16/17, p. 85-116, 1965

BIGARELlA, J. J; MOUSINHO, M. R; SILVA, J. X. da. Pediplanos, pedimentos e seus depósitos correlativos no Brasil. 
Boletim Paranaense de Geografia, n. 16/17, p. 117-149, 1965.

BIGARELLA, J. J. et al. Estrutura e Origem das Paisagens tropicais e Subtropicais. 2. ed. Florianópolis: Editora da UFSC, v. 1,2009

CASTRO, S. S. Impregnação de amostras de solo para confecção de lâminas delgadas. Boletim Informativo da Sociedade Brasileira de Ciência do Solo, v.15, 44 f., 1985.

CASTRO, S. S. Micromorfologia de solos: bases para descrição de lâminas delgadas. Campinas/Goiânia: UNICAMP/UFG, 2008

CORREA, A. C. B. Dinâmica geomorfológica dos compartimentos elevados do Planalto da Borborema, Nordeste do Brasil. 2001. 386 f. Tese (Doutorado em Geografia) - Universidade Estadual Paulista, Rio Claro, SP, 2001.

CHURCHMAN, G. J. The key role of micromorphology in studies of the genesis of clay minerals and their associations in soils and its relevance to advances in the philosophy of soil science. Turkish Journal of Earth Sciences, v.22, p.376-390, 2013.

CPRM - SERVIÇO GEOLÓGICO DO BRASIL. Mapa geológico da Bacia Sedimentar do Araripe, 2007.

DE OLIVEIRA, P. E. BARRETO, A. M. F; SUGUIO, K. Late Pleistocene/Holocene climatic and vegetational history of the Brazilian caatinga: the fossil dunes of the middle São Francisco River. Palaeogeography, Palaeoclimatology, Palaeoecology, v.152, p.319-337, 1999.

FERNANDES, A. Fitogeografia brasileira - Províncias florísticas. 2a parte. 3. ed. Fortaleza: Realce editora e indústria gráfica, 2006.

FERREIRA, G. M. S. S; OLIVEIRA, M. A. T. Aplicação da Micromorfologia de Solos ao Estudo de Sedimentos AlúvioColuviais em Cabeceiras de Vale. Pesquisas em Geociências, v.33, p.3-18, 2006

FLEMMING, B.W. A revised textural classification of gravelfree muddy sediments on the basis of ternary diagrams. Continental Shelf Research, v.20, p.1125-1137, 2000.

FONSECA, D. N. Reconstrução da Paisagem Geomorfológica através da Assinatura Geoquímica dos eventos deposicionais da bacia do rio Capibaribe-Mirim, Pernambuco. 2012.167f. Dissertação (Mestrado em Geografia) - Universidade Federal de Pernambuco, Recife, PE, 2012.

Fundação Cearense de Meteorologia e Recursos Hídricos (FUNCEME). Zoneamento geoambiental do Ceará: Parte II - Mesorregião do sul cearense. Fortaleza, 2006.
Fundação Cearense de Meteorologia e Recursos Hídricos (FUNCEME). Levantamento de reconhecimento de média intensidade dos solos - Mesorregião do Sul Cearense. Fortaleza, 2012. 280p.

Fundação Cearense de Meteorologia e Recursos Hídricos (FUNCEME). Índice de Aridez para o Ceará. Acesso em maio de 2015.

GALE, S. J; HOARE, P. G. Quaternary sediments: petrographic methods for the study of ulithified rocks. Londres: Bethaven Press, 1991, 318 p.

GALVÃO, D. C. Reconstrução paleoambiental a partir dos colúvios do entorno da lagoa do puiu, município de Ibimirim - Pernambuco, Recife (PE). 2012. 127f. Dissertação (Mestrado em Geografia) - Universidade Federal de Pernambuco, Recife, PE, 2012.

GOUDIE, A. S; BULL, P. A. Slope process change and colluvium deposition In Swaziland: an sem analysis. Earth surface processes and landforms, v.9, p.289-299, 1984

GUERRA, S; PAISANI, J. C. Levantamento estratigráfico das Formações Superficiais Cenozóicas no Planalto de Palmas (PR) e Água Doce (SC): subsídio ao estudo da evolução da paisagem a partir do Estágio Isotópico Marinho 3. Ambiência (UNICENTRO), v. 8, p.651-665, 2012.

GURGEL, S. P. P; BEZERRA, F. H. R; CORREA, A. C. B; MARQUES, F. O; MAIA, R. P. Cenozoic uplift and erosion of structural landforms in NE Brazil. Geomorphology, v.186, p. 68-84, 2013.

INMET - Instituto Nacional de Meteorologia. Normais Climatológicas do Brasil 1961-1990: http:/www.inmet.gov. br/portal/index.php? $\mathrm{r}=$ clima/normaisClimatologicas. Acesso em junho de 2015

KNOX, J. C. Valley alluviation in southwestern Wisconsin. Annals of the Association of American Geographers, v.62, p.401-410, 1972.

KEMP, R. A. Micromorphology of loess-paleosol sequences: a record of paleoenvironmental change. Catena, v.35, p.179-196, 1999.

Instituto Brasileiro de Geografia e Estatística (IBGE). Série “Mapas Murais". 2002 http://www.ibge.gov.br/home/ geociencias/recursosnaturais/mapas/mapas_doc4.shtm. Acesso em junho de 2015 .

KÜHN, P; PIETSCH, D. Soil micromorphogenesis and Early Holocene paleoclimate at the desert margin of Southern Arabia. Spanish journal of soil science, v.3, n.2, p. 59-77, 2013. 
LEOPOLD, M; VÖLKEL, J. Colluvium: definition, differentiation, and possible suitability for reconstructing holocene climate data. Quaternary International, v.162-163, p.133-140, 2007.

LIMA, F. J. de. Evolução geomorfológica e reconstrução paleoambiental do setor subúmido do Planalto Sedimentar do Araripe: um estudo a partir dos depósitos coluviais localizados nos municípios de Crato e Barbalha - Ceará. 2015. 192 f. Tese (Doutorado em Geografia) - Universidade Federal de Pernambuco, Recife, PE, 2015.

MAACK, R. Notas preliminares sobre clima, solos e vegetação do Estado do Paraná. Arquivos de Biologia e Tecnologia, v. III, p.103-225, 1948.

MAACK, R. Notas complementares à apresentação preliminar do mapa fitogeográfico do Estado do Paraná (Brasil). Arquivos do Museu Paranaense, v. VII, p.351-361, 1949.

MAACK, R. Geografia física do Estado do Paraná. $2^{\text {a }}$.ed .Rio de Janeiro: J. Olympio/Curitiba, 442p. 1981.

MABESOONE, J. M. Relief of northeastern Brazil and its correlated sediments. Zeitschrift für geomorphologie, Annals of Geomorphology, Berlin, p. 419-453, 1966.

MABESOONE, J. M; CASTRO, C. Desenvolvimento geomorfológico do Nordeste brasileiro, B. Soc. Geol. Núcleo Nordeste, v. 3, p. 5-36, 1975.

MESTDAGH, H; HAESAERTS, P; DODONOY, A; HUS, J. Pedosedimentary and climatic reconstruction of the last interglacial and early glacial loess-paleosol sequence in South Tadzhikistan. Catena v.35, p.197-218, 1999.

MILLAR, S. W. S. Processes dominating macro-fabric generation in periglacial colluvium. Catena, v.67, p.79-87, 2006.

MOdenesi-GAUtTiERI, M. C; TOledo, M. C. M. Weathering and formation of hillslope deposits in the tropical highlands of Itatiaia - south-eastern Brazil. Catena, v.27, p.81104, 1996.

MOUSINHO, M. R; BIGARELLA, J. J. Movimentos de massa no transporte dos detritos da meteorização das rochas. Boletim Paranaense de Geografia, n.16/17, p.43- 84, 1965.

MOURA, J. R. da S; SILVA, T. M. da. Complexo de rampas de colúvio. In: CUNHA, S. B. de; GUERRA, A. J. T. (Org.). Geomorfologia do Brasil. 7. ed. Rio de Janeiro: Bertrand Brasil, 2011. p: 144-180.

MROCZEK, P; RODZIK, J. Genetic interpretation of micromorphological features of gully loess-soil deposits (case study: Kolonia Celejów, E Poland). Landform Analysis, v. 17, p.125-130,2011.

MÜCHER, H; STEIJN, H. V; KWAAD, F. Colluvial and Mass Wasting deposits. In: STOOPS, G; MARCELINO, V; MEES, F. (Org.). Interpretation of Micromorphological Features of Soils and Regoliths. Oxford, UK: Elsevier, 2010, p. 37-48.

MUTZENBERG, D. S. Gênese e ocupação pré-histórica do Sítio Arqueológico Pedrado Alexandre: uma abordagem a partir da caracterização paleoambiental do Vale do Rio Carnaúba - RN. 2007. 142 f. Dissertação (Mestrado em Arqueologia) Universidade Federal de Pernambuco, Recife, PE, 2007.

MUTZENBERG, D. S. Ambientes de Ocupação Pré-Histórica no Boqueirão da Pedra Furada, Parque Nacional Serra da Capivara - PI. 2010. 256 f. Tese (Doutorado em Arqueologia) - Universidade Federal de Pernambuco, Recife, PE, 2010

NARDY, A. J. R. OLIVEIRA, M. A. F; BETANCOURT, R. H. S; VERDUGO, D. R. H; MACHADO, F. B. Geologia e estratigrafia da Formação Serra Geral. Geociências, v.21(1/2), p.15-32, 2002.

NEUMANN, V. H; BORREGO, A. G; CABRERA, L; DINO, R. Organic matter composition and distribution through the Aptian-Albian lacustrine sequences of the Araripe Basin, northeastern Brazil. International Journal of Coal Geology. v.54, p.21-40, 2003.

PAISANI, J. C. Estratigrafia, significado paleoambiental e evolução de rampa arenosa/dissipação no Balneário Praia Mole - Ilha de Santa Catarina. 2004. 295f. Tese (Doutorado em Geografia) - Universidade Federal de Santa Catarina, Florianópolis, SC, 2004.

PAISANI, J. C; GEREMIA, F. Evolução de encostas no planalto basáltico com base na análise de depósitos de colúvio - médio vale do rio marrecas, SW do Paraná. Geociências, São Paulo, UNESP, v. 29, n. 3, p. 321-334, 2010

PAisAni, J. C; PONTELli, M. E. Propriedades micromorfológicas de colúvios em encosta no médio vale do Rio Marrecas (Sudoeste do Estado do Paraná) - bases para distinção de formações superficiais alóctones e autóctones em substrato basáltico. Pesquisas em Geociências, 39(1): 53-62, 2012.

PAISANI, J. C; PONTELLI, M. E; CALEGARI, M. R. Evolução de bacias de baixa ordem nos 41.000 anos AP - Brasil meridional. Mercator (Fortaleza. Online), v.11, p. 131-148, 2012.

PAISANI, J. C; PONTELLI, M. E; CORREA, A. C. B; RODRIGUES, R. A. R. Pedogeochemistry and micromorphology of oxisols - A basis for understanding etchplanation in the Araucárias Plateau (Southern Brazil) in the Late Quaternary. 
Journal of South American Earth Sciences, v.48, p.1-12, 2013a.

PAISANI, J. C; CALEGARI, M. R; PONTELLI, M. E; PESSENDA, L. C. R; CORREA, A. C. de B; PAISANI, S. D. L; RAITZ, E. O papel das mudanças climáticas do Quaternário Superior na dinâmica evolutiva de paleovale de segunda ordem (Sul do Brasil). Revista Brasileira de Geomorfologia, v.14, n.1, p.103-116, 2013b. (DOI: http://dx.doi.org/10.20502/rbg.v14i1)

PAISANI, J. C; PONTELLI, M. E; OSTERRIETH, M. L; PAISANI, S. D. L; FACHIN, A; GUERRA, S; OLIVEIRA, L. Paleosols in low-order streams and valley heads in the Araucaria Plateau - Record of continental environmental conditions in southern Brazil at the end of MIS 3. Journal of South American Earth Sciences, v. 54, p. 57-70, 2014.

PAISANI, J. C; FACHIN, A; PONTELLI, M. E; OSTERRIETH, M. L; PAISANI, S. D. L; FUJITA, R. H. Evolução de paleocabeceira de drenagem do Rio Chopinzinho (Sul do Brasil) durante o Quaternário Superior. Revista Brasileira de Geomorfologia, v.17, n.1, p.43-59, 2016. (DOI: http://dx.doi. org/10.20502/rbg.v17i1.735)

PEUVAST, J. P; CLAUDINO SALES, V. Aplainamento e geodinâmica: revisitando um problema clássico em geomorfologia. Mercator (Fortaleza. Online), v.1, n.1, p.113150,2002

PONTELLI, M. E. Pedomorfoestratigrafia de depósitos de leques aluviais: Bacia do Rio Itoupava, sul do Estado de Santa Catarina. 2005. 220f. Tese (Doutorado em Geografia) Universidade Federal de Santa Catarina, Florianópolis, SC, 2005.

RAITZ, E. Coleção de referência de silicofitólitos da flora do sudoeste do Paraná: subsídios para estudos paleoambientais. 2012. 153f. Dissertação (Mestrado em Geografia), Universidade Estadual do Oeste do Paraná - UNIOESTE, Campus Francisco Beltrão, 2012.

RANULPHO, R. Fitólitos em sedimentos coluviais do Quaternário Superior no Planalto Sedimentar do Araripe: Significado paleoambiental. Dissertação (Mestrado em Geografia) - Universidade Federal do Pernambuco, Recife, PE (No prelo).

SELBY, M, J. Earth`s Changing surface: an introduction to geomorphology. London: Clarendon, 1985.

SHEPARD, F. P. Nomenclature based on sand - silt - clay ratios. Journal of Sedimentary Petrology, v. 24, p.151-158, 1954.

SILVA, A. J. P; LOPES, R. da C; VASCONCELOS, A. M;
BAHIA, R. B. C. Bacias Sedimentares Paleozóicas e MesoCenozóicas Interiores. In: BIZZI, L. A.; SCHOBBENHAUS, C.; VIDOTTI, R. M.; GONÇALVES, J. H. (org.) Geologia, Tectônica e Recursos Minerais do Brasil. Brasília: CPRM, 2003. p. 55-85.

SILVA, D. G. da. Evolução Paleoambiental dos depósitos de tanques em Fazenda Nova, Município de Brejo da Madre de Deus - Pernambuco. 2007. 155 f. Dissertação (Mestrado em Geografia) - Universidade Federal de Pernambuco, Recife, PE, 2007.

SILVA, D. G. da. Reconstrução da dinâmica geomorfológica do semiárido brasileiro no Quaternário superior a partir de uma abordagem multiproxy. 2013. 277 f. Tese (Doutorado em Geografia) - Universidade Federal de Penambuco, Recife, PE, 2013.

SOUZA, M. J. N. Bases naturais e esboço do zoneamento geoambiental do estado do Ceara. In: LIMA, L. C. (Org) Compartimentação territorial e gestão regional do Ceará. Fortaleza: Funece, 2000. p. 06-104.

STOOPS, G. Guidelines for analysis and description of soil and regolith thin sections. Soil Science Society of America, Madison, WI, 184f., 2003

STOOPS, G; MARCELINO, V; MEES, F. (Org.). Interpretation of Micromorphological Features of Soils and Regoliths. Oxford, UK: Elsevier, 2010.

SUGUIO, K. Introdução à sedimentologia. São Paulo, Edgard Blücher, 1973.

SUGUIO, K. Geologia sedimentar. São Paulo: Edgard Blücher, 2003.

TAVARES, B. A. C. A participação da morfoestrutura na gênese da compartimentação geomorfológica do gráben do Cariatá, Paraíba. Recife, PE. 2010. 137 f. Dissertação (Mestrado em Geografia) - Universidade Federal de Pernambuco, Recife, PE, 2010.

TAVARES, B. A. C. Evolução morfotectônica dos pedimentos embutidos do Planalto da Borborema. Recife, PE. 2015. $251 \mathrm{f}$. Tese (Doutorado em Geografia). UFPE, 2015.

THOMAS, M. F. Geomorpholoqy in the Tropics: a study of weatherinq and denudation in low latitudes. Chichester: John Wiley \& Sons, Ltd., 1994.

WIEDER, M; GVIRTZMAN, G. Micromorphological indications on the nature of the Late Quaternary Paleosols in the southern coastal plain of Israel. Catena, v.35, p. 219-237, 1999. 